\title{
Nociceptor and Hair Cell Transducer Properties of TRPA1, a Channel for Pain and Hearing
}

\author{
Keiichi Nagata, ${ }^{1}$ Anne Duggan, ${ }^{1,4}$ Gagan Kumar, ${ }^{1}$ and Jaime García-Añoveros ${ }^{1,2,3,4}$ \\ Departments of ${ }^{1}$ Anesthesiology, ${ }^{2}$ Physiology, and ${ }^{3}$ Neurology, ${ }^{4}$ Northwestern University Institute for Neuroscience, Northwestern University Feinberg \\ School of Medicine, Chicago, Illinois 60611
}

\begin{abstract}
Mechanosensory channels of sensory cells mediate the sensations of hearing, touch, and some forms of pain. The TRPA1 (a member of the TRP family of ion channel proteins) channel is activated by pain-producing chemicals, and its inhibition impairs hair cell mechanotransduction. As shown here and previously, TRPA1 is expressed by hair cells as well as by most nociceptors (small neurons of dorsal root, trigeminal, and nodose ganglia) and localizes to their sensory terminals (mechanosensory stereocilia and peripheral free nerves, respectively). Thus, TRPA1 channels are proposed to mediate transduction in both hair cells and nociceptors. Accordingly, we find that heterologously expressed TRPA1 display channel behaviors expected for both auditory and nociceptive transducers. First, TRPA1 and the hair cell transducer share a unique set of pore properties not described for any other channel (block by gadolinium, amiloride, gentamicin, and ruthenium red, a ranging conductance of $\sim 100 \mathrm{pS}$ that is reduced to $54 \%$ by calcium, permeating calcium-induced potentiation followed by closure, and reopening by depolarization), supporting a direct role of TRPA1 as a pore-forming subunit of the hair cell transducer. Second, TRPA1 channels inactivate in hyperpolarized cells but remain open in depolarized cells. This property provides a mechanism for the lack of desensitization, coincidence detection, and allodynia that characterize pain by allowing a sensory neuron to respond constantly to sustained stimulation that is suprathreshold (i.e., noxious) and yet permitting the same cell to ignore sustained stimulation that is subthreshold (i.e., innocuous). Our results support a TRPA1 role in both nociceptor and hair cell transduction.
\end{abstract}

Key words: nociceptor; hair cell; transduction; channel; desensitization; mechanosensory; pain; auditory; adaptation; multisensory; cochlea; nodose

\section{Introduction}

Vertebrate hair cells are specialized mechanosensors of the inner ear that detect sound, gravity, and other accelerations, and allow us to hear and keep balance. The apical surface of hair cells is characterized by a protruding bundle of actin-rich stereocilia that form the mechanosensory organelle. Models of mechanotransduction, supported by ample physiological and anatomical evidence, imply the presence of one or two mechanosensory channel complexes at or near the top of each stereocilia, connected with each other via an extracellular structure called the tip link and to the actin cytoskeleton via myosin motor proteins. The deflection of stereocilia results in tension to gate the channels and thus generates the mechanoreceptor current (Pickles and Corey, 1992; Gillespie and Walker, 2001).

Mechanosensory channels are also present in many cells, including neurons of somatosensory ganglia. Whereas large somatosensory neurons are low-threshold mechanosensors that

Received Jan. 3, 2005; revised March 9, 2005; accepted March 10, 2005.

This work was supported by National Institute of Neurological Disorders and Stroke Grant R01-NS044363 and National Institute on Deafness and Other Communication Disorders Grant R21-DC006089 (J.G.-A.). We thank Peter Dallos, Steve H. DeVries, Jeff R. Holt, and Jay Z. Yeh for comments.

Correspondence should be addressed to Dr. Jaime García-Añoveros, Departments of Anesthesiology, Physiology and Neurology, Northwestern University Institute for Neuroscience, Ward 10-070, 303 East Chicago Avenue, Chicago, IL 60611. E-mail: anoveros@northwestern.edu.

D0I:10.1523/JNEUROSCI.0013-05.2005

Copyright $\odot 2005$ Society for Neuroscience $\quad$ 0270-6474/05/254052-10\$15.00/0 detect innocuous touch and proprioception, small somatosensory neurons are thought of as nociceptors and detect thermal, chemical, and mechanical (high-threshold) stimuli. Many of these small neurons are polymodal and detect more than one type of noxious stimulus.

TRPA1 (also known as ANKTM1 and P120) (Jaquemar et al., 1999) is a member of branch A of the transient receptor potential (TRP) family of cation channels. It has been reported that TRPA1 is expressed in a small number (3.6\%) of small DRG neurons, and that it forms channels activated by icilin, a chemical that induces a cooling sensation, and by temperatures $\leq 17^{\circ} \mathrm{C}$, and thus is proposed to be the painful cold receptor (Story et al., 2003). A more general role in pain is also consistent with reports that TRPA1 is expressed by a larger percentage of neonatal rat trigeminal ganglia neurons (Jordt et al., 2004) and that it forms channels that gate in response to pungent chemicals, such as isothiocyanates (Bandell et al., 2004; Jordt et al., 2004). Thus, there is some uncertainty as to the expression pattern and function of TRPA1 in somatosensory neurons, although it is believed to play a role in the transduction of pain.

In addition to the transmembrane domains characteristic of all TRP channels, TRPA1 is characterized by a large number (17) of ankyrin repeats, a feature in common with another TRP channel, NOMPC (no mechanoreceptor potential C) (TRPN1), that in flies mediates bristle mechanoreception (Walker et al., 2000) and in zebrafish contributes to hair cell mechanoreception (Sidi 
et al., 2003). However, there is no NOMPC ortholog in mammals. TRPA1 has also been implicated in hair cell transduction, by our report that its inhibition impairs transduction and that one antibody to TRPA1 immunoreacts to hair cell stereocilia (Corey et al., 2004). We wondered whether TRPA1 would be part of transduction channels in both mammalian nociceptors and hair cells. Here, we present conclusive evidence that TRPA1, in addition to being expressed in nociceptor neurons, is present in hair cell stereocilia. We also demonstrate that heterologously expressed TRPA1 channels display a unique combination of channel properties - not reported for any other channel-in common with the endogenous hair cell transducer, as well as a mechanism of calcium-induced, voltage-dependent inactivation that could account for nociceptor properties such as lack of desensitization, coincidence detection, and allodynia.

\section{Materials and Methods}

\section{In situ hybridization}

A 1055 bp cDNA fragment corresponding to codons 727-1078 (from transmembrane domain 1 to past 6 ) of mouse TRPA1 was subcloned into pCRII (Invitrogen, San Diego, CA) and linearized with NotI (to make an antisense probe with SP6 RNA polymerase) or with BamH1 (to make a control, sense probe with T7 RNA polymerase). cRNA probes were labeled with digoxigenin-UTP (Roche, Basel, Switzerland).

Mouse ganglia and organs were snap-frozen to $-30^{\circ} \mathrm{C}$ in dry icecooled isopentane, sectioned to a thickness of $10 \mu \mathrm{m}$ in a cryostat, and hybridized as described previously (Schaeren-Wiemers and Gerfin-Moser, 1993). Neuron size was measured with MetaMorph software. To prevent the counting of cells from adjacent sections more than once, and because the larger nuclei were $\sim 5 \mu \mathrm{m}$ in radius (one-half of the thickness of the section), only cells sectioned through the middle of the nucleus were considered.

\section{Antibodies, Western blots, and immunohistochemistry}

Generation of TRPA1 antisera. DNA encoding the first 60 aa of TRPA1 was amplified from cDNA and subcloned into the EcoRI and SalI sites of gex6p1 (Amersham Biosciences, Piscataway, NJ). The fusion protein glutathione $S$-transferase (GST)::TRPA1(1-60) was expressed in Escherichia coli, purified with glutathione Sepharose (Amersham Biosciences), and then used by the Center of Comparative Medicine at Northwestern University to immunize rabbits and generate the 316 antisera. Antibodies recognizing GST were removed from the antisera with GST-agarose (Pierce, Rockford, IL). The 316 antisera was further purified on protein A-agarose (Pierce) and affinity-purified with GST::TRPA1(1-60), which was covalently bound to agarose using the AminoLink Plus kit (Pierce).

Immunoblot. HEK 293 cells were transfected with an expression vector containing the mouse TRPA1 cDNA under the control of the cytomegalovirus (CMV) promoter or with empty vector using Fugene-6 (Roche Molecular Biochemicals). Cells were lysed $24 \mathrm{~h}$ after transfection with radioimmunoprecipitation assay buffer [50 mM Tris, pH 8.0, $150 \mathrm{~mm}$ $\mathrm{NaCl}, 5 \mathrm{~mm}$ EDTA, $1 \% \mathrm{NP}-40,0.5 \%$ sodium deoxycholate, and $0.1 \%$ SDS containing Complete protease inhibitors (Roche Molecular Biochemicals)]. Lysates were clarified by centrifugation at 20,000 $\times g$ for 30 min, mixed with an equal volume of $2 \times$ SDS sample buffer, and heated at $100^{\circ} \mathrm{C}$ for $5 \mathrm{~min}$. Alternatively, transfected cells were lysed directly in $2 \times$ SDS sample buffer containing $8 \mathrm{~m}$ urea and protease inhibitors, and heated at $85^{\circ} \mathrm{C}$. Mouse organs of Corti, saccules plus utricles, cervical dorsal root ganglia, and trigeminal ganglia were homogenized in $2 \times$ SDS sample buffer and heated to $100^{\circ} \mathrm{C}$ for $5 \mathrm{~min}$. Rat peripheral nerve lysate was purchased (BD Biosciences). All of the lysates were separated by SDS-PAGE and transferred to polyvinylidene difluoride membrane. Affinity-purified antibody 316 was detected with horseradish peroxidase-coupled donkey anti-rabbit IgG and the ECL Plus kit (Amersham Biosciences).

Immunohistochemistry (IHC) on cryostat sections and whole mounts was performed as described previously (García-Añoveros et al., 2001; Duggan et al., 2002). Antibody $316(2.5 \mu \mathrm{g} / \mathrm{ml})$ was preincubated with either GST or with the antigenic peptide, GST::TRPA1 (1-60), in 100X excess. Whole mounts of organ of Corti, saccule, utricle, and crista ampullaris were dissected from 4 -week-old Swiss Webster mice.

\section{Electrophysiology}

Channel expression. HEK 293 cells were transiently transfected with mouse TRPA1 cDNA under the CMV promoter by lipofectamine. Cells were used for patch-clamp experiments $24-48 \mathrm{~h}$ after transfection.

Whole-cell current recording. Membrane currents were recorded using the whole-cell patch-clamp technique at room temperature $\left(23^{\circ} \mathrm{C}\right) . \mathrm{Pi}-$ pette electrodes were made from $0.8 \mathrm{~mm}$ (inner diameter) borosilicate glass capillary tubes (Kimax 51; Kimble Glass). The electrodes had resistances of 4-6 M $\Omega$ when filled with internal solution. The membrane potential was clamped at $-80 \mathrm{mV}$, and a $5-10 \mathrm{~min}$ period was allowed after rupture of the membrane to equilibrate the cell interior with pipette solution. Currents through the electrode were recorded by an Axopatch 200B amplifier (Axon Instruments), filtered at $10 \mathrm{kHz}$, and stored on the computer via an analog-digital converter (DIGIDATA 1332A; Axon Instruments). Protocols were controlled by pClamp 9.0 software (Axon Instruments).

Single-channel current recording. Single-channel currents were recorded from cell-attached and outside-out patches at room temperature $\left(23^{\circ} \mathrm{C}\right)$. Pipette electrodes were coated by SigmaCote (Sigma, St. Louis, $\mathrm{MO})$ to minimize background noise. Currents through the electrode were filtered at $2 \mathrm{kHz}$. Only those events $>200 \mu$ s of data were considered to be accurate in the analysis. Opening and closing of the channels were detected using the $50 \%$ threshold criterion.

Solutions. The external bath solution for both whole-cell and cellattached patch-clamp experiments contained the following (in mM): 140 $\mathrm{NaCl}, 5 \mathrm{KCl}, 2 \mathrm{CaCl}_{2}, 1 \mathrm{MgCl}_{2}$, and 10 HEPES. The $\mathrm{pH}$ was adjusted to 7.4 with $\mathrm{NaOH}$, and the osmolarity was adjusted to $310 \mathrm{mOsm}$ by D-glucose. The internal pipette solution for the whole-cell and outsideout patch-clamp experiments contained the following (in mM): $140 \mathrm{CsCl}$, 10 EGTA, 10 HEPES, and $2 \mathrm{Mg}$-ATP. The $\mathrm{pH}$ was adjusted to 7.4 with $\mathrm{CsOH}$, and the osmolarity was $300 \mathrm{mOsm}$.

Test solutions. Allyl isothiocyanate (AITC), ruthenium red, and icilin were first dissolved in dimethylsulfoxide (DMSO). These stock solutions were then diluted with the standard external solution to make test solutions. Final concentration of DMSO was $<0.3 \%(\mathrm{v} / \mathrm{v})$. Test solutions were applied through the multibarrel FastStep perfusion system (SF-77B; Warner Instruments). Test solutions flowed continuously through one of three glass barrels. The cell/membrane patch was exposed to the solution from one barrel and switched to the next solution from a different barrel by a computer-controlled switch, allowing an exchange of the solution surrounding a whole cell within $60 \mathrm{~ms}$ and an outside- out patch in $<10 \mathrm{~ms}$.

\section{Results}

TRPA1 is exclusively expressed by most nociceptors and hair cells, and localized to sensory endings and stereocilia

By in situ hybridization, we find TRPA1 mRNA in the three ganglia (dorsal root, trigeminal, and nodose) that contain nociceptive neurons (Fig. 1a-i) as well as, weakly, in the organ of Corti of the inner ear (data not shown), but find no TRPA1 mRNA in brain, heart, liver, kidney, skeletal muscle, lung, spleen, testis, whiskerpad skin, or superior cervical ganglion (Fig. 1j; and supplemental Fig. S1, available at www.jneurosci.org as supplemental material). Within sensory ganglia of adult mice, TRPA1 is expressed by $56.5 \%$ of all DRG neurons, $36.5 \%$ of all trigeminal ganglia neurons, and $28.4 \%$ of all nodose ganglia neurons. Size distribution plots (Fig. 1) show that, in all three types of ganglia, expression is restricted to the majority of the smaller neurons, the nociceptors ( $~ 75 \%$ in DRG; with an average size of $364 \pm 212$ $\mu \mathrm{m}^{2}$; mean $\left.\pm \mathrm{SD}\right)$. Because painful cold-sensitive neurons represent only 3.6\% of DRG neurons (Story et al., 2003; Jordt et al., 2004), the much wider distribution of TRPA1 implies that it serves another function (such as mechanonociception?) that is displayed by most pain neurons. Indeed, we (see Fig. 4b) and 

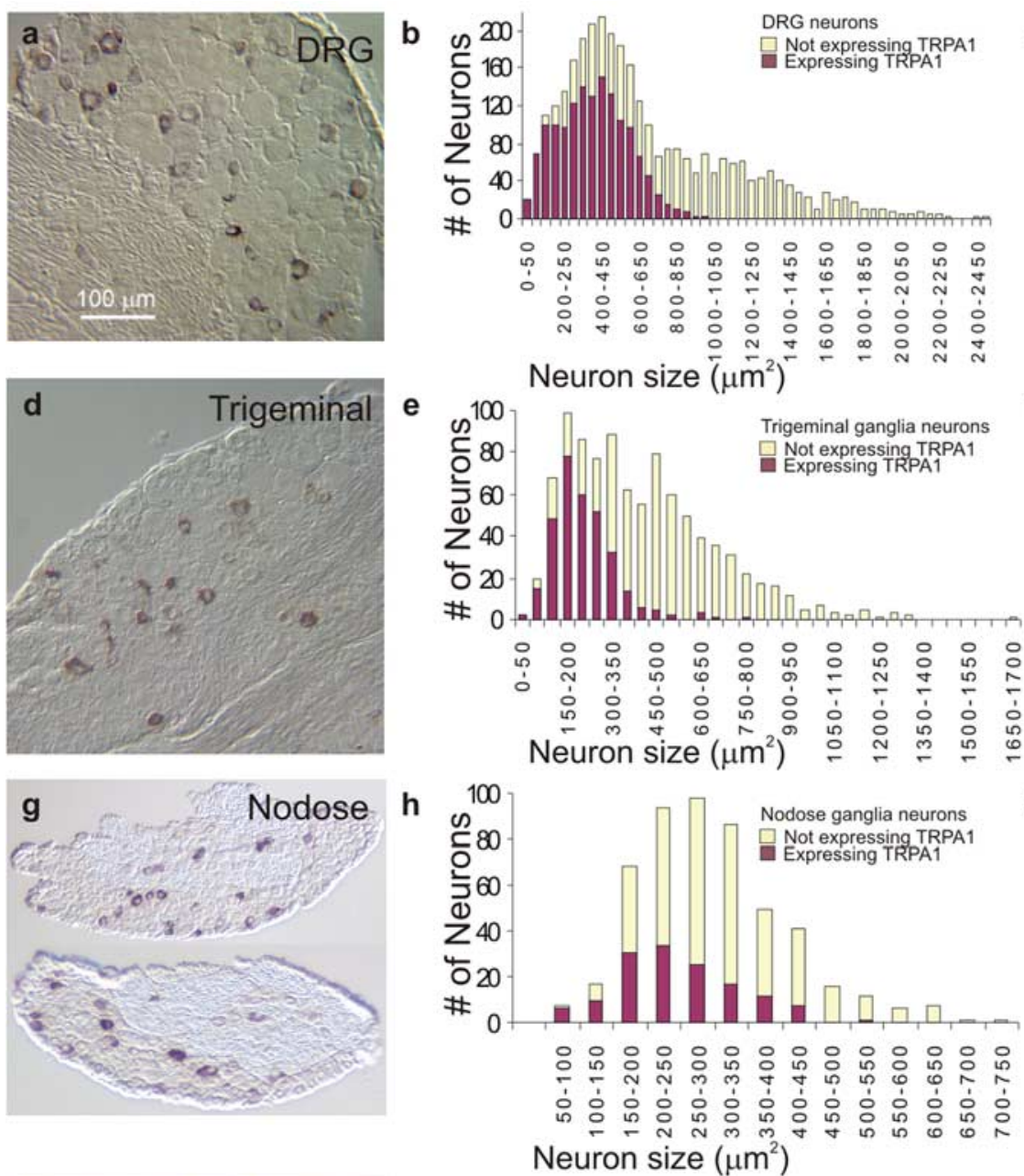
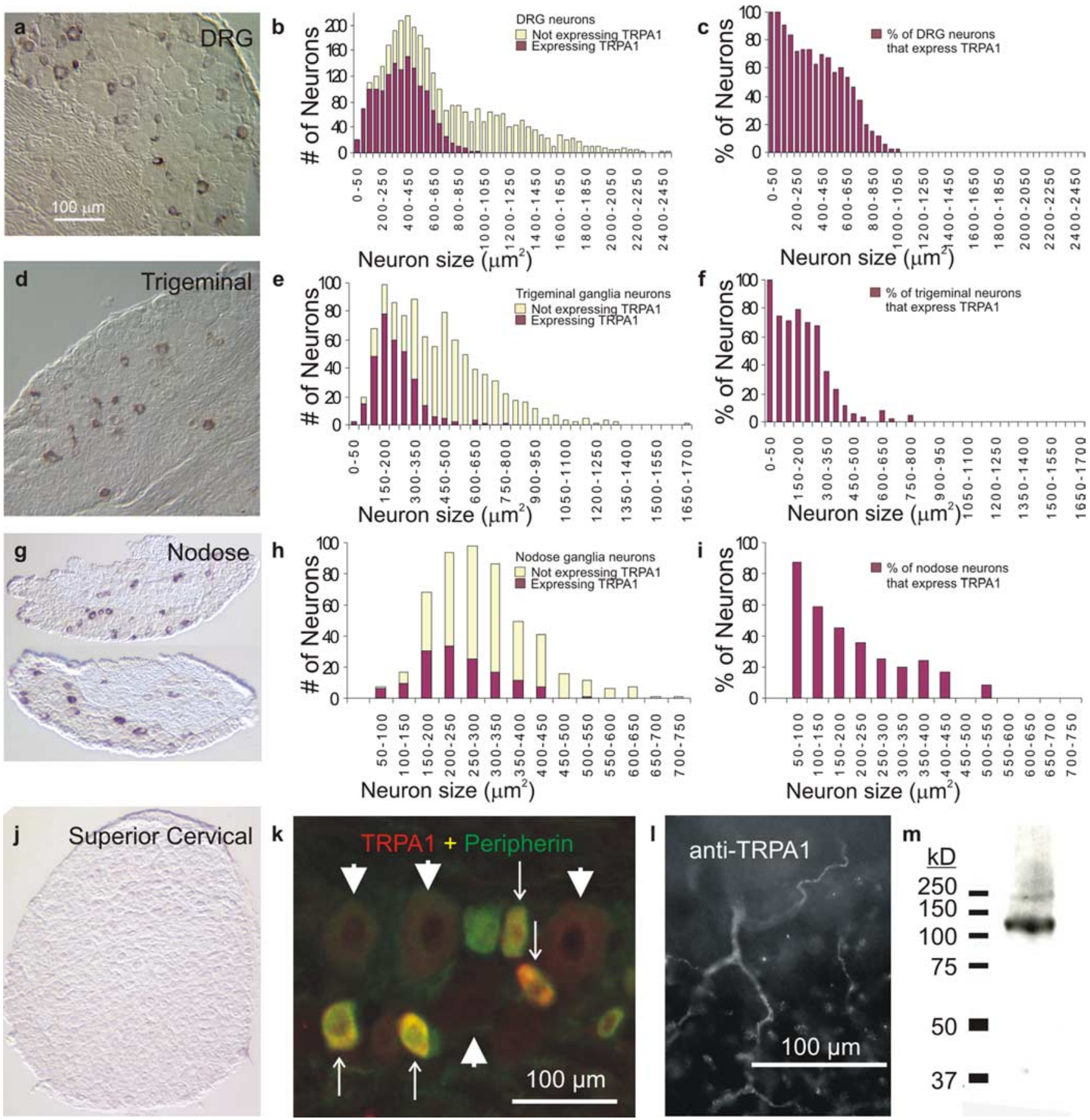

Figure 1. Mouse TRPA1 is expressed by most nociceptors and localized to peripheral sensory fibers. $\boldsymbol{a}-\boldsymbol{j}$, TRPA1 mRNA is detected by in situ hybridization in the majority of the nociceptors from dorsal root $[n=2904$ cells from 29 sections of a postnatal day 37 (P37) CD1 mouse] ( $\boldsymbol{a}-\boldsymbol{c}$ ), trigeminal ( $n=988$ cells from 19 sections of a P180 (BA/CAJ mouse) (d-f $)$, and nodose ganglia $(n=$ 504 cells from 20 sections of a young adult CD1 mouse) ( $\boldsymbol{g}-\boldsymbol{i})$, but not in superior cervical ganglia (of a young adult (D1 mouse) ( $)$ ), which lacks nociceptive neurons. $\boldsymbol{k}-\boldsymbol{m}$, With antibodies, TRPA1 protein $(\boldsymbol{k})$ is also detected in the soma of small diameter, peripherin-positive nociceptive neurons from trigeminal ganglia (arrows) but not in the large diameter ones (arrowheads), as well as in the nociceptive sensory processes that innervate the bladder epithelium (I). $\boldsymbol{m}$, The same antibodies detect an expected band of $\sim 128 \mathrm{kDa}$ in Western blots from peripheral nerve lysate.

others (Jordt et al., 2004) could not elicit cold activation of heterologously expressed TRPA1 channels.

We raised antibodies to the $\mathrm{N}$-terminal 60 residues of mouse TRPA1 and used them to detect TRPA1 by both Western blots and IHC. By both methods, our affinity-purified antisera recognized HEK cells transfected to express TRPA1 and not control HEKs (transfected with a plasmid not expressing TRPA1) (data not shown). It should be noted that, on Western blots, although our anti-TRPA1 antisera recognized only one band, this was larger than predicted by its amino acid sequence unless urea was added to the protein. Our interpretation is that TRPA1 has an anomalous mobility on standard SDS-PAGE gels. However, both in Western blots and with IHC, label was eliminated by incubation of the antibody with excess antigenic peptide. Thus, our antiserum specifically recognizes mouse TRPA1.

We used this affinity-purified antiserum on tissue sections and whole mounts to confirm the expression of TRPA1 in small, peripherin-positive (nociceptive) neurons of sensory ganglia and to dem- 

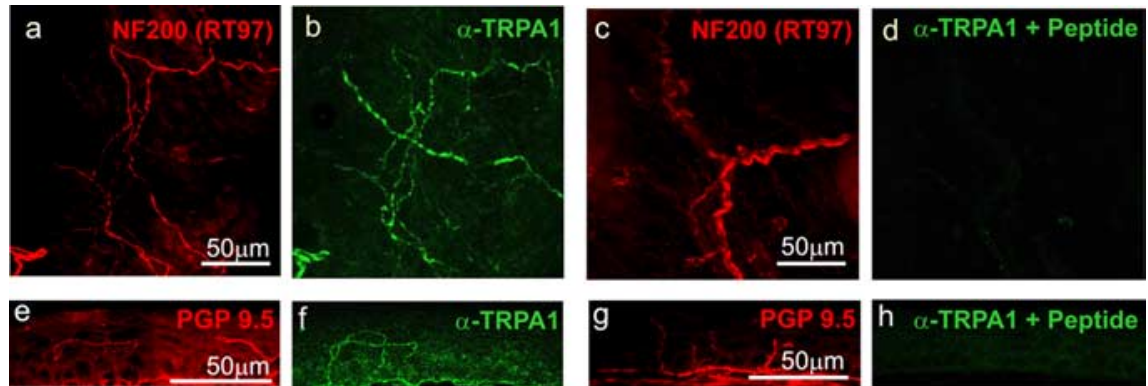

Figure 2. Mouse TRPA1 protein in nociceptive nerve fibers that innervate the trigone of the bladder $(\boldsymbol{a}-\boldsymbol{d})$ and the cornea $(\boldsymbol{e}-\boldsymbol{h}) . \boldsymbol{a}-\boldsymbol{d}$, The nerves are labeled in red with anti-neurofilament [RT97 (for $\boldsymbol{a}, \boldsymbol{c}$ ) and PGP9.5 (for $\boldsymbol{e}, \boldsymbol{g}$ )], and anti-TRPA1 immunoreactivity is indicated in green $(\boldsymbol{b}, \boldsymbol{f}, \boldsymbol{d}, \boldsymbol{h}) . \boldsymbol{b}, \boldsymbol{f}$, TRPA 1 immunoreactivity in the presence of GST protein. $\boldsymbol{d}, \boldsymbol{h}$, Elimination of the TRPA1 immunoreactivity in the presence of antigenic peptide (a fusion of GST to the N-terminal 60 residues of TRPA1).
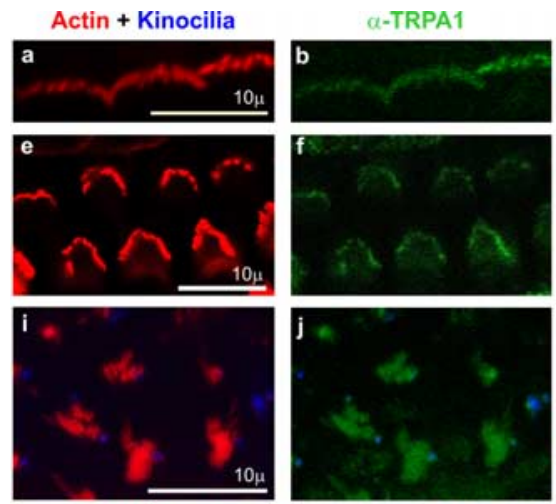

Actin + Kinocilia
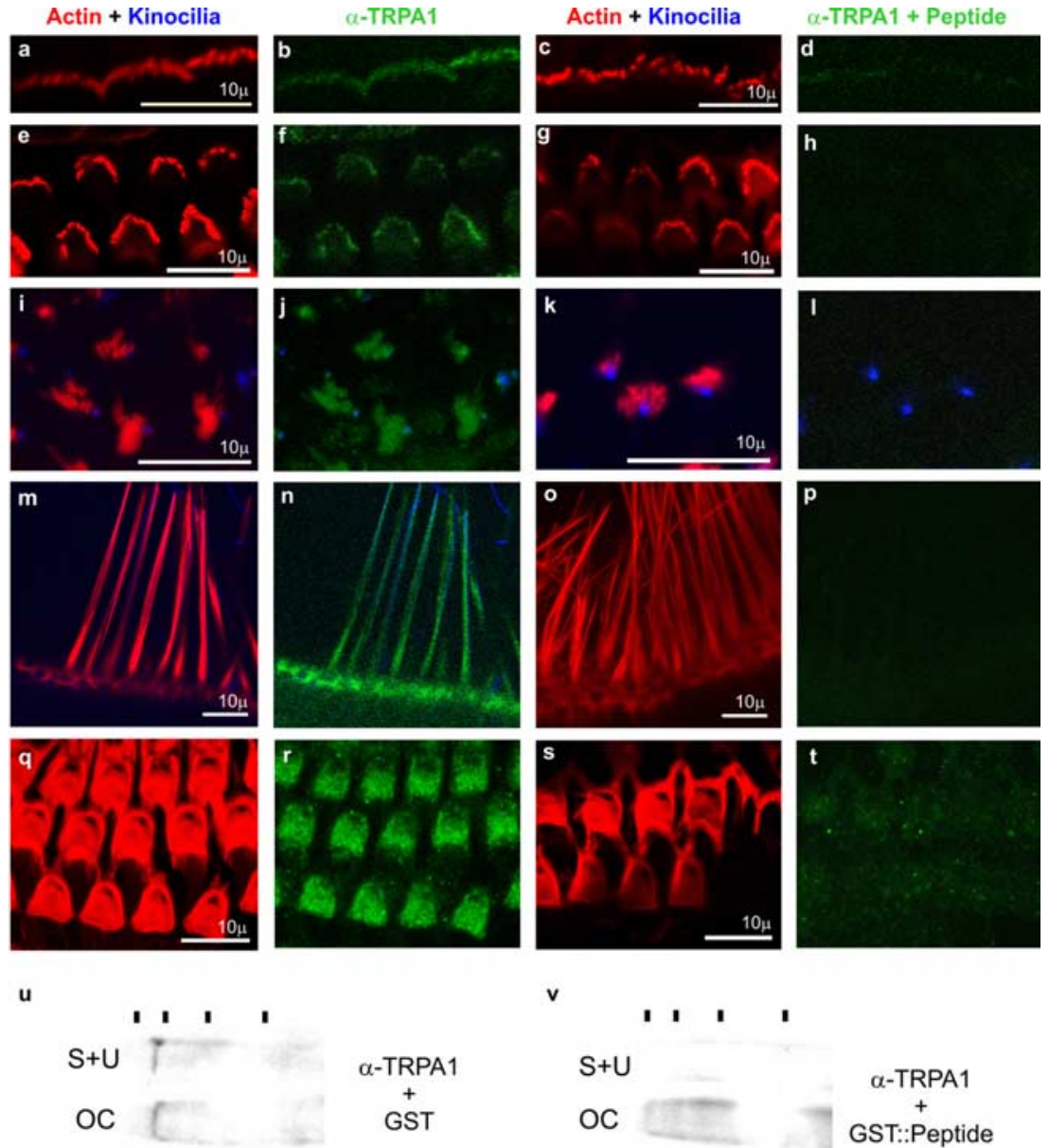

Figure 3. Mouse TRPA1 is expressed in the inner ear and localizes to the mechanosensory hair cell bundles. Anti-TRPA1 immunoreactivity is indicated in green; actin-rich hair cell bundles, labeled with phalloidin, are indicated in red; and kinocilia, labeled with anti-tubulin antibodies, are in blue. The two columns at the left show TRPA1 immunoreactivity in the presence of GST protein, whereas the two columns at the right show elimination of the TRPA1 immunoreactivity in the presence of antigenic peptide (a fusion of GST to the N-terminal 60 residues of TRPA1). TRPA1 immunoreactivity specifically labels the stereocilliary bundles of inner hair cells $(\boldsymbol{a}-\boldsymbol{d})$, outer hair cells $(\boldsymbol{e}-\boldsymbol{h})$, utricular hair cells $(\boldsymbol{i}-\boldsymbol{I})$, and hair cells of the crista ampullaris $(\boldsymbol{m}-\boldsymbol{p})$, as well as the apical side (the actin-rich cuticular plate) of outer hair cells $(\boldsymbol{q}-\boldsymbol{t})$. The label is not detected at the basal side of hair cells (not shown). $\boldsymbol{u}, \boldsymbol{v}$, Western blots reveal a single band detected by anti-TRPA1 on protein lysates from mouse saccule plus utricle $(\mathrm{S}+\mathrm{U})$ and organ of Corti $(0 \mathrm{C})$.

onstrate its localization to their sensory processes in target organs such as the trigone of the bladder and the cornea, which are primarily innervated by nociceptive ( $\mathrm{C}$ and $\mathrm{A} \delta$ ) fibers (Figs. $1 k-m, 2)$. These immunoreactivities were eliminated by competition with excess an-

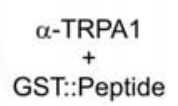

tigenic peptide. Localization of TRPA1 to nociceptive terminals is consistent with its expression by most small- and mediumdiameter DRG neurons, and necessary for TRPA1 to participate in their primary sensory transduction.

Because, in addition to finding TRPA1 mRNA in most nociceptor neurons, in situ signal was also detected in the organ of Corti, we used the anti-TRPA1 antibody to determine the precise distribution of this protein in inner ear (Fig. 3). Western blots revealed a single band from mouse organ of Corti and from mouse utricle plus saccule, and both were eliminated by competition with excess antigenic peptide, demonstrating its specificity for TRPA1 (Fig. $3 u, v)$. Immunohistochemistry revealed anti-TRPA1 immunoreactivity in mouse hair cells of the cochlea (inner and outer hair cells) (Fig. $3 a-h)$, utricle $(i-l)$, saccule, and crista ampullaris $(m-p)$. In all types of hair cells, anti-TRPA1 immunoreactivity was localized at the apical side at the cuticular plate and at the bundles of stereocilia, the mechanosensory specializations of hair cells. All of these immunoreactivities were abolished by incubation with excess antigenic peptide (a GST::TRPA1-N terminus fusion protein) (Fig. $3 c, d, g, h, k, l, o, p, s, t)$ but not by GST alone $(a, b, e, f, i, j, m, n, q, r)$. We conclude that TRPA1 is expressed in hair cells of the inner ear and that it localizes to the stereocilia, the subcellular sites of transduction. We thus wondered whether TRPA1, which is believed to form a receptor channel in nociceptor neurons, also forms part of the mechanosensory transducer channel complex of hair cells.

\section{Blockers of mechanosensory channels also block TRPA1}

Although receptor potentials have not been recorded from nociceptive terminals, extensive recordings from hair cells provide a detailed description of their transduction channels. We characterized TRPA1 heterologously expressed in HEK 293 cells and compared its channel properties with those known for the transducer of hair cells as well as those that might be expected for a transducer of nociceptors. The hair cell transducer is a macromolecular complex with accessory proteins [such as the membrane-spanning cadherin 23 (Siemens et al., 2004), myosins that form a motor for slow adaptation, etc.] in association with one or more types of channel proteins (in zebrafish, these possibly include NOMPC). If TRPA1 is part of the channel complex, we expect that some of its pore properties would be reproduced by heterologously expressed TRPA1 channels, even if these are likely to form homomultimers with no accessory proteins. We 
found that TRPA1 and the hair cell transducer display a similar pharmacological profile and also share a rare combination of biophysical channel properties.

Although the hair cell transducer is activated by mechanical stimulation, this requires macromolecular attachments that are unlikely to be present in a heterologous cell. Instead, we activated the channels with the previously reported TRPA1 agonists AITC (the pungent component of wasabi) and icilin (Story et al., 2003; Bandell et al., 2004; Jordt et al., 2004) (Fig. $4 a, b)$. This activation is extremely slow, and probably requires partitioning of the agonists into the membrane or the mediation of second messengers (for example, channels in cell-attached patches can be activated by application of AITC to the bath). Despite the difference in expression system and mode of activation, we found that heterologously expressed TRPA1 and the endogenous hair cell mechanotransducing channel have a remarkably similar pharmacological profile.

TRPA1 channels, activated by AITC in the absence of extracellular calcium (to avoid calcium-induced effects, which might interfere with the effects of other antagonists) (see below), were blocked by gentamicin, $\mathrm{Gd}^{3+}$, amiloride, and ruthenium red (Fig. $4 c$, $d$ and Table 1 ). These are all of the known blockers - with similar affinities - of mechanosensitive channels of several types (Hamill and McBride, 1996), including those of hair cells (Table 1). The Hill coefficient for each of the four antagonists was indistinguishable between the hair cell transducer and TRPA1, consistent with a similar mechanism of action for both channels. Quantitative differences were observed for the $\mathrm{IC}_{50}$ of $\mathrm{Gd}^{3+}$ (a 100fold difference) and amiloride (a 10-fold difference), both of which are thought to block the hair cell transducer by binding outside of the pore. Amiloride and its analogs block by interacting with an extracellular part of the channel that is outside of the electric field of the pore, with an affinity that correlates to their lipophilicity (Rüsch et al., 1994). Gd ${ }^{3+}$ has been postulated to interact with the lipid membrane to antagonize mechanosensitive channels (Yang and Sachs, 1989; Hamill and McBride, 1996). In both cases, it is foreseeable that accessory proteins would get in the way or facilitate the effects on the pore-forming portion of the channel, to which TRPA1 is more likely to contribute. However, gentamicin and ruthenium red are thought to block the hair cell transducer by binding to its pore (Kroese et al., 1989; Farris et al., 2004), and as expected, they both block TRPA1 with almost identical $\mathrm{IC}_{50}$.

Unfortunately, none of these four blockers are specific to the hair cell transducer. All four block other mechanosensitive channels, and each one also blocks other channels that are not mechanosensitive (Hamill and McBride, 1996). In particular, ruthe- b

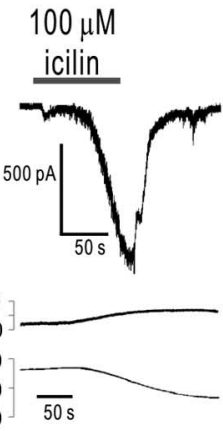

d
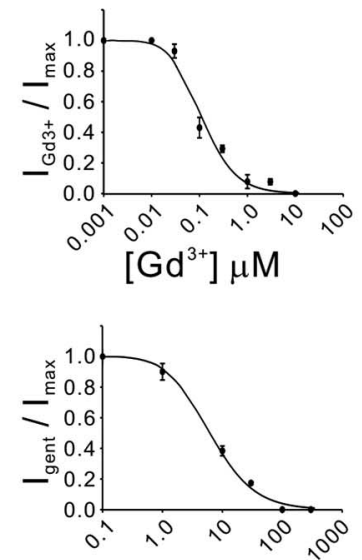

[Gentamicin] $\mu \mathrm{M}$

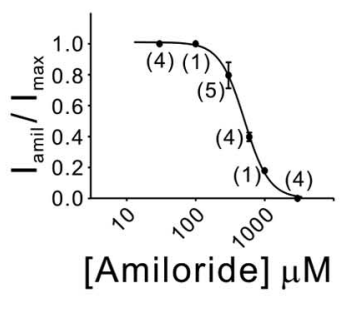

Figure 4. Agonists and antagonists of TRPA1 channels heterologously expressed in HEK 293 cells. $\boldsymbol{a}-\boldsymbol{c}$, Currents elicited by exposure of TRPA1 channels to AITC ( $\boldsymbol{a}$ ) (which appear complex, with a slow activation component followed by a faster one and then by inactivation) and icilin (b), but not by cold temperatures, are blocked by gentamicin, amiloride (AMIL), gadolinium, and ruthenium red (RR) $(\boldsymbol{c}, \boldsymbol{d})$. All blockers were tested in the absence of extracellular calcium to distinguish block from calciuminduced channel closure. $\boldsymbol{d}$, Dose-response curves for gadolinium $(n=4)$, gentamicin $(n=4)$, and amiloride (number of cells

Table 1. Blockers of TRPA1 channels in HEK activated by AITC and of the endogenous mechanotransducer channel of hair cells activated mechanically

\begin{tabular}{ll||cl}
\hline Blocker & TRPA1 in HEKs & Hair cell transducer & References \\
\hline Gentamicin-IC 50 & $6.7 \pm 0.68 \mu \mathrm{M}$ & $7.6 \mu \mathrm{M}$ & (Kroese et al., 1989) \\
Gentamicin-Hill coefficient & 1.16 & 1.18 & (Kroese et al., 1989) \\
Ruthenium red-IC 50 & $3.44 \pm 0.09 \mu \mathrm{M}$ & $3.6 \pm 0.3 \mu \mathrm{M}$ & (Farris et al., 2004) \\
Ruthenium red-Hill coefficient $^{3+}-\mathrm{C}_{50}$ & $1.13 \pm 0.03$ & $1.4 \pm 0.2$ & (Farris et al., 2004) \\
$\mathrm{Gd}^{3+}$ & $0.10 \pm 0.02 \mu \mathrm{M}$ & $10.1 \mu \mathrm{M}$ & (Kimitsuki et al., 1996) \\
$\mathrm{Gd}^{3+}-H i l l$ coefficient & $1.17 \pm 0.25$ & 1.14 & (Kimitsuki et al., 1996) \\
Amiloride-IC 50 & $511 \pm 11.7 \mu \mathrm{M}$ & $50 \mu \mathrm{M}$ & (Jorgensen and Ohmori, 1988; \\
& & & Rüsch et al., 1994) \\
Amiloride-Hill coefficient & $2.43 \pm 0.12$ & $2.2 \pm 0.1$ & (Ricci, 2002) \\
\hline
\end{tabular}

Note that although blocking effects on TRPA1 were tested in the absence of external calcium to avoid calcium-induced potentiation and inactivation, the blocking effects on hair cells were tested in the presence of external calcium, because in its absence, the tip links disassemble and mechanotransduction is blocking effects on hair cells were tested in the presence of exter
abolished. Data for TRPA1 show mean \pm confidence interval.

nium red and gadolinium are known to block other TRP channels. Although the similarity in pharmacological profile is consistent with TRPA1 forming part of the hair cell-transducing complex, the possibility of this being coincidental cannot be ruled out. Are other less common properties of the hair cell transducer displayed by heterologously expressed TRPA1?

\section{Same effects of permeating calcium (potentiation and} closure) on TRPA1 and the hair cell transducer

Extracellular calcium has characteristic modulatory effects on the transduction channel of hair cells. As calcium enters the channel, it first causes a potentiation of the transducer current [a decrease in the time course of activation, measured from ensemble averages of single-channel records (Ricci et al., 2003)] but then causes 

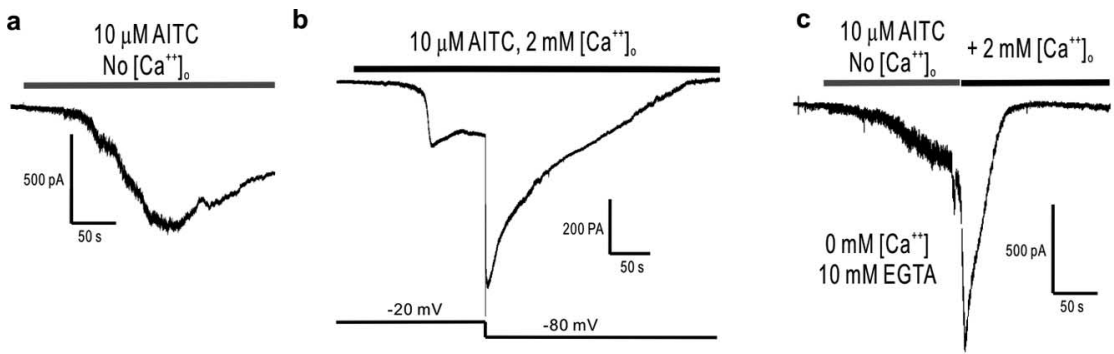

d

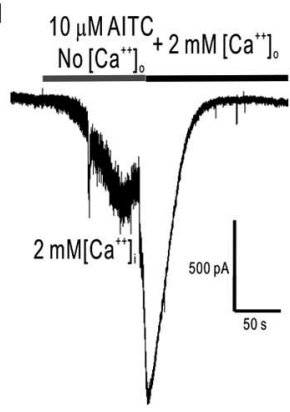

e

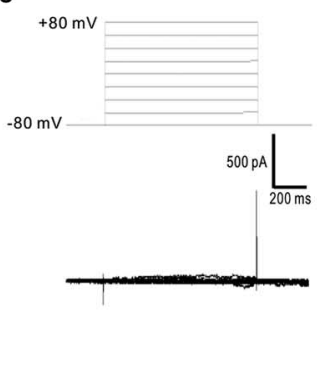

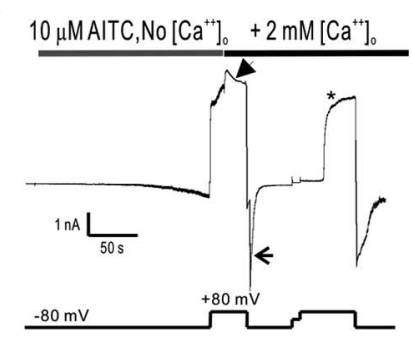

Figure 5. Calcium-induced potentiation and inactivation of TRPA1 is voltage dependent, and the inactivation is reversed by sustained depolarization. $\boldsymbol{a}, \boldsymbol{b}$, In the absence $(\boldsymbol{a})$ of external calcium, AITC elicits only slow activation ( $-80 \mathrm{mV}$ holding potential), whereas in the presence $(\boldsymbol{b})$ of external calcium, inactivation is complete at hyperpolarized $(-80 \mathrm{mV})$ holding potentials but not at depolarized $(-20 \mathrm{mV}$ ) potentials. c, Addition of calcium to the external medium of slowly activated TRPA1 channels elicits fast potentiation followed by inactivation ( $-80 \mathrm{mV}$ holding potential). Notice that intracellular calcium is being chelated with $10 \mathrm{~mm}$ EGTA. $\boldsymbol{d}$, The calcium-induced potentiation and subsequent inactivation of TRPA1 channels also occurs with high ( 2 and $3 \mathrm{~mm}$ ) levels of internal calcium (introduced by diffusion from the pipette, under the whole-cell configuration, over a period of $>5 \mathrm{~min}$ ). $\boldsymbol{e}$, Whole-cell recordings of TRPA1-expressing HEK cells exposed to several voltage steps reveal no voltage-dependent gating of TRPA1 channels in the range of -80 to $+80 \mathrm{mV}$. $f$, However, calcium-induced inactivation, which is reduced at positive $(+80$ $\mathrm{mV}$ ) membrane potentials (arrowhead) and maximal at negative $(-80 \mathrm{mV})$ ones (arrow), is reversed by positive holding potentials (asterisk) after a delay of $\sim 30 \mathrm{~s}$. The mechanism for this recovery from inactivation is presently unknown. No $\left[\mathrm{Ca}^{2+}\right]_{0}$ solutions contain $10 \mathrm{~mm}$ EGTA as chelator and have no $\mathrm{CaCl}_{2}$ added. For all panels, the trace shown is a representative of at least four separate cells.

Table 2. Single-channel parameters of AITC-induced activation (in the absence of external $\mathrm{Ca}^{2+}$ ), $\mathrm{Ca}^{2+}$-induced potentiation, and $\mathrm{Ca}^{2+}$-induced inactivation obtained from outside- out patches at a holding potential of $-80 \mathrm{mV}$

\begin{tabular}{llllcl}
\hline Phase & $P_{\text {open }}$ & $\begin{array}{l}\text { Burst duration } \\
(\mathrm{ms})\end{array}$ & $\begin{array}{l}\text { Open time } \\
(\mathrm{ms})\end{array}$ & $\begin{array}{l}\text { Close time } \\
(\mathrm{ms})\end{array}$ & $\begin{array}{l}\text { Amplitude } \\
(\mathrm{pA})\end{array}$ \\
\hline $\mathrm{Ca}^{2+}$-free activation & $0.17 \pm 0.11$ & $11.7 \pm 24.4$ & $4.4 \pm 5.9$ & $78.5 \pm 177$ & $5.7 \pm 0.4$ \\
$\mathrm{Ca}^{2+}$-induced potentiation & $0.51 \pm 0.30$ & $94.2 \pm 133$ & $6.1 \pm 8.9$ & $7.4 \pm 25.6$ & $3.1 \pm 0.4$ \\
$\mathrm{Ca}^{2+}$-induced inactivation & $0.02 \pm 0.01$ & $4.1 \pm 1.3$ & $\mathrm{ND}$ & $\mathrm{ND}$ & $3.1 \pm 0.4$
\end{tabular}

Data show mean \pm SD estimated from 1117 events pooled from four separate experiments. ND, Not determined.

channel closure, a better known phenomenon referred to as fast adaptation, by binding to a site in the channel itself or close to it (Howard and Hudspeth, 1988; Ricci et al., 1998; Kennedy et al., 2003). We found that, as with the hair cell transducer channel, calcium entering through TRPA1 also causes potentiation (i.e., faster activation) followed by closure.

Activation of TRPA1 channels by AITC is slow and complex, with a slow phase of activation, followed by a faster phase of activation, and then by closure (henceforth referred to as inactivation) (Fig. 4a). By removing external calcium (and adding $10 \mathrm{~mm}$ EGTA as chelator), we found that slow activation was present but that faster activation and inactivation were absent or significantly slowed (Fig. 5a). Thus, inactivation requires external calcium. In addition, inactivation is voltage dependent, taking place at a holding potential of $-80 \mathrm{mV}$ but not of $-20 \mathrm{mV}$ (Fig. $5 \mathrm{~b}$ ), which suggests that external calcium must enter through the channel to close it.

Indeed, although adding extracellular calcium to closed chan- nels (i.e., not previously activated with AITC) did not induce activation, adding extracellular calcium to channels already opened by AITC (and at a holding potential of $-80 \mathrm{mV}$, so that calcium would permeate the channel) suddenly induced potentiation followed by inactivation (Fig. $5 c$ ). An enhancement of current rate and magnitude by extracellular calcium had been noticed previously by Jordt et al. (2004), who also reported that a rise in intracellular calcium attributable to release from intracellular stores can activate the TRPA1 channel in the plasma membrane. Thus, one possibility is that a rise in intracellular calcium induces channel potentiation and/or inactivation. However, external calcium caused potentiation and inactivation when intracellular calcium was chelated with $10 \mathrm{~mm}$ EGTA or BAPTA (Fig. $5 c$ and data not shown). In addition, up to $3 \mathrm{~mm}$ calcium in the internal solution caused no channel activation (no currents were detected after reaching the whole-cell configuration with calcium in the pipette), nor did it cause potentiation and inactivation to channels opened by AITC. Instead, potentiation and inactivation of AITCopened channels in cells already loaded with internal calcium only occurred when external calcium was added (Fig. 5d). These effects of external calcium were much more pronounced at hyperpolarized potentials [at $-80 \mathrm{mV}$, current was potentiated by $305.3 \pm 95.4 \%(n=7)$, and inactivated with a time constant $\left(\tau_{\mathrm{i}}\right)$ of $3.5 \mathrm{~s}$ ] than at depolarized potentials [at +80 $\mathrm{mV}$, potentiation was $3.8 \pm 2.4 \%(n=7)$; $\tau_{\mathrm{i}}=30.0 \mathrm{~s}$ ] (Fig. 5f, compare arrow with arrowhead and with $c$ and $d$ ). Thus, maximal potentiation and inactivation are the effects of externally applied calcium to the open channel at a hyperpolarized potential. We conclude that, for extracellular calcium to cause potentiation and inactivation, channels must open and allow permeating calcium ions to bind to a site that is within or very close to the pore, very much as is thought to affect the hair cell transducer (Howard and Hudspeth, 1988; Kennedy et al., 2003). Despite these mechanistic similarities, the potentiation and fast adaptation of the hair cell transducer are much faster, taking milliseconds, rather than seconds. These quantitative differences of timing likely depend on the affinity of calcium for its binding site in the channel, affinity that would depend on the microenvironment close to the pore and thus could vary substantially between a homomultimeric TRPA1 channel and a heteromultimeric transducer channel complex endogenous to hair cells.

\section{Depolarization reopening of calcium-inactivated TRPA1 channels}

Once the hair cell transducer channels have been closed (adapted) by entering calcium, depolarization to $+80 \mathrm{mV}$ causes their reopening (Ricci et al., 2000). We found that TRPA1 chan- 
nels displayed the same property. Although voltage steps up to $+80 \mathrm{mV}$ caused no activation of TRPA1 (Fig. $5 e$ ), they did cause recovery from calcium-induced inactivation ( $f$, asterisk). The reopening of calcium-inactivated TRPA1 channels at $+80 \mathrm{mV}$ took place after a long delay ( $\sim 30 \mathrm{~s})$, a phenomenon for which we presently have no explanation.

The antagonizing effect of depolarization on inactivation (or desensitization) is particularly wanting for a nociceptive receptor channel, which would be expected to ignore sustained subthreshold (innocuous) stimuli but to respond to suprathreshold (noxious) stimuli and remain active as long as they persist, as well as to be sensitized by activation of other nociceptor channels expressed in the same sensory terminals. Indeed, at $-20 \mathrm{mV}$, a potential reached by small DRG neurons on sustained stimulation (Blair and Bean, 2003), TRPA1 channels do not fully inactivate and remain open while stimulated by AITC (Fig. $5 b$; compare currents at $-20 \mathrm{mV}$ with those at $-80 \mathrm{mV}$ and with those of Fig. $4 a$ ). Thus, depolarization of a nociceptive neuron, whether by activation of TRPA1 or by other channels (such as the capsaicin receptor TRPV1), would prevent or delay inactivation of TRPA1 channels, perhaps accounting for the lack of desensitization and even some forms of sensitization (such as allodynia) and coincidence detection characteristic of pain.

\section{Similarities in single-channel properties of TRPA1 and the} hair cell transducer

We found that TRPA1 and the hair cell transducer have a similar unitary conductance and that it is equally affected by calcium. With normal external solution, a TRPA1 channel had a conductance of $98 \pm 13 \mathrm{pS}$ at $-60 \mathrm{mV}$ (Fig. $6 c$ ), similar to the $\sim 100 \mathrm{pS}$ estimates (which range from 87 to $163 \mathrm{pS}$ with high external calcium) obtained for hair cell channels of several vertebrates (Crawford et al., 1991; Denk et al., 1995; Géléoc et al., 1997; Ricci et al., 2003). Because the estimates of single-channel conductance for the hair cell transducer are so varied, we believe it would be more informative to compare the effects of external calcium on this conductance, which is to reduce it to 54\% (Ricci et al., 2003).

Using outside-out patches, activation, potentiation, and inactivation were analyzed at the single-channel level (Fig. $6 a$ and Table 2). The slow, non-desensitizing activation caused by AITC in the absence of external calcium results from a switch to a large conductance $(5.7 \pm 0.4 \mathrm{pA})$ but flickering channel (with mean open time, $4.4 \pm 5.9 \mathrm{~ms}$; mean closed time, $78.5 \pm 177 \mathrm{~ms}$; burst duration, $11.7 \pm 24.4 \mathrm{~ms} ; P_{\text {open }}, 0.17 \pm 0.11$; activation phase), which may account for the high noise of this phase under wholecell mode (Figs. $5 c, d ; 6 a$, whole-cell trace). On addition of external calcium, the channel first transitions to a state (the potentiation phase) with low conductance $(3.1 \pm 0.4 \mathrm{pA})$ but high open probability $\left(P_{\text {open }}, 0.51 \pm 0.30\right)$, prolonged burst duration (94.2 $\pm 133 \mathrm{~ms}$; potentiation phase), slightly increased open time $(6.1 \pm 8.9 \mathrm{~ms})$, and decreased closed time $(7.4 \pm 25.6 \mathrm{~ms})$. This transient potentiation phase is then followed by an inactivation phase $\left(P_{\text {open }}, 0.02 \pm 0.01\right.$; burst duration, $\left.4.1 \pm 1.3 \mathrm{~ms}\right)$. These changes in single-channel parameters correspond in time with, and can explain, the calcium-induced potentiation followed by inactivation in whole-cell experiments.

Notably, the unitary conductance of both TRPA1 and the hair cell transducer are reduced by calcium to the same extent: $53.7 \pm$ $2.0 \%$ (estimated from six separate patches) for TRPA1 versus $54 \%$ for the hair cell transducer (Ricci et al., 2003).

It has been recently reported that, in turtle hair cells, the transduction channel displays not one but a range of conductance levels, which are distributed tonotopically along the cochlea a
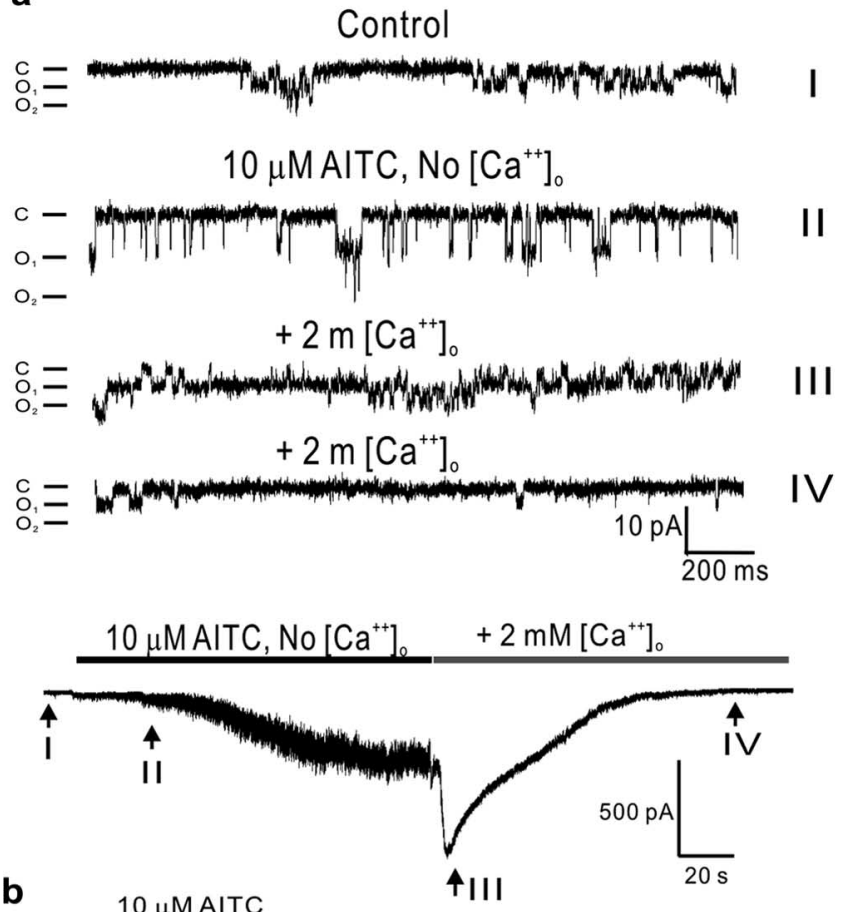

b
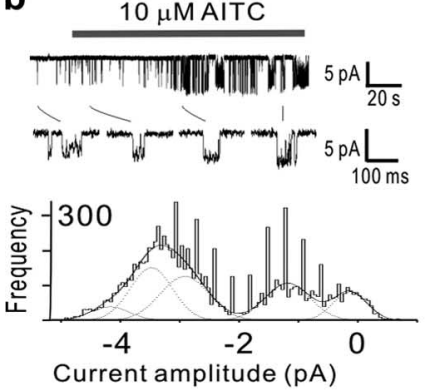

$+2 \mathrm{mM}\left[\mathrm{Ca}^{++}\right]$。
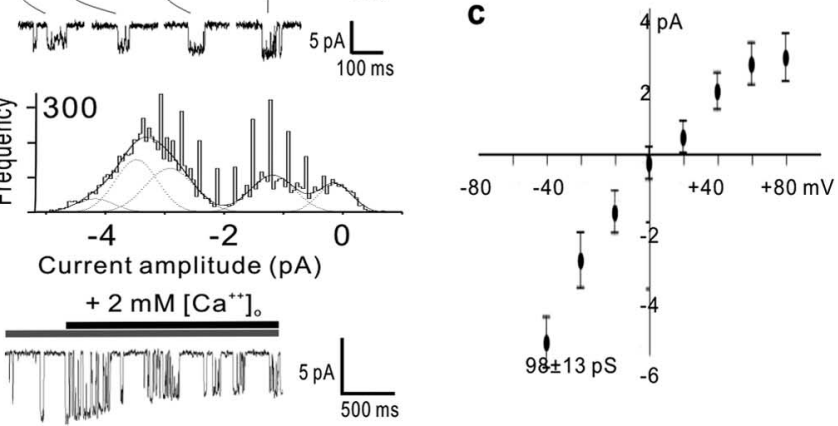

Figure 6. Single-channel properties of TRPA1. $\boldsymbol{a}$, Recapitulation of TRPA1 slow activation, calcium-induced potentiation, and subsequent inactivation at the single-channel level in outside- out patches (at a holding potential of $-80 \mathrm{mV}$ ). AITC, in the absence of calcium, activates a large conductance, flickery channel (II, activation) that, on exposure to calcium, transitions to a low conductance but high open-probability state (III, potentiation) followed by a low openprobability state (IV, inactivation). The bottom trace is a whole-cell record, obtained just before patch formation, indicating (in roman numerals) the times that correspond to the singlechannel traces above. $\boldsymbol{b}$, Transitions between low and high single-channel currents reveal a multitude of intermediate conductance levels for TRPA1 channels. Top trace, Cell-attached patch (with standard external solution in the pipette; amplitudes of 3.4, 4.1, 4.6, and 4.9 pA). Middle trace, Amplitude histograms of currents induced by application of AITC. Curves superimposed on the histograms are five Gaussian fits to the data points. At least four conductance levels were discerned. Bottom trace, Outside- out patch at a holding potential of $-80 \mathrm{mV}$ (amplitudes ranging continuously from 6.4 to $3.3 \mathrm{pA}$ ). c, Current-voltage relationship of a representative TRPA 1 channel, with a conductance of $98 \mathrm{pS}$ at $-60 \mathrm{mV}$, activated with $10 \mu \mathrm{m}$ AITC and recorded on a cell-attached patch with standard external solution in the pipette. For all panels, the trace shown is a representative of at least four separate membrane patches. Error bars in $\mathrm{c}$ represent confidence interval. C, Channels closed; $0_{1}$, one channel open; $0_{2}$, two channels open.

(Ricci et al., 2003). This unusual phenomenon could occur either if hair cells along the cochlea express different channels or if they express the same type of channel, just one with the ability to assume multiple conductance states. We did notice, by looking at the single-channel conductance changes caused by AITC activa- 
tion on a cell-attached patch or by external calcium addition to an outside-out patch, that TRPA1 channels display not just two but a range of conductance states (Fig. 6b) (notice that, with our perfusion system, $2 \mathrm{~mm}$ external calcium is reached in $<10 \mathrm{~ms}$, yet the unitary conductance gradually decreases over the next second; $\tau=909 \pm 165 \mathrm{~ms}$ ).

We further analyzed the amplitude histograms and clearly discerned multiple conductance levels of single-channel currents induced by AITC (Fig. 6b, middle panel). External calcium concentration did not change in these experiments. There were at least four conductance levels (and probably many more, as is apparent from the bottom trace of Fig. $6 b$, although they would occur with insufficient frequency to be detected in a frequency histogram) with $1.2,2.9,3.4$, and $4.2 \mathrm{pA}$, respectively. Because there were no overlapped currents during recordings, we concluded that these currents were induced by one channel instead of multiple channels with different conductance. Thus, our data indicate that the TRPA1 channel has multiple conductance states. Perhaps, in each hair cell along the cochlea, only one of these states is displayed.

\section{Discussion}

TRPA1 is expressed by nociceptor neurons and hair cells; in both, it localizes to the sensory end of the cell (the free nerve endings and the bundles of stereocilia), and although it can be activated by pain-producing chemicals, its interference in vertebrate hair cells impairs mechanotransduction. All of this evidence indicates that TRPA1 plays roles in both nociceptive and auditory cell function.

TRPA1 as a pore-forming subunit of the hair cell transducer In a separate study, some of us have reported, using an antibody to the $\mathrm{C}$ terminus of TRPA1, an immunoreactivity to the cuticular plates and the mechanosensory stereocilia of hair cells (Corey et al., 2004). This suggestive result, on its own, is inconclusive because of the possibility of cross-immunoreactivity. Here, we report an analogous immunoreactivity with another antibody raised against another part of TRPA1, the $\mathrm{N}$ terminus. Our antibody localization is further substantiated with Western blots from inner ear (which reveal a single band) and with controlled peptide competitions (GST::peptide vs GST), which indicate that the protein detected is indeed TRPA1. Together, both antibodies provide decisive evidence for the presence of TRPA1 in hair cell stereocilia.

The presence of TRPA1 in hair cell bundles is consistent with a role in mechanosensory transduction. In addition, the presence of TRPA1 in the cuticular plates is also consistent with a role in transduction, because this area of the hair cell, which also contains myosin 1c (the presumed adaptation motor) (Hasson et al., 1997) and cadherin 23 (the presumed tip link) (Siemens et al., 2004), is thought of as a repository of transducer proteins. Indeed, we reported that inhibition of mammalian TRPA1 by RNA interference, and of zebrafish TRPA1 by morpholinos, both compromised transduction, resulting in a significant reduction and sometimes complete elimination of transduction currents (Corey et al., 2004). We therefore think that TRPA1 contributes to the hair cell transduction channel complex, perhaps as a poreforming component. If TRPA 1 is indeed a pore-forming subunit, then we expect similarities in pore properties between heterologously expressed TRPA1 and the hair cell transducer channel. Accordingly, we find properties that are strikingly similar (although not identical). The pharmacological profile is analogous, and nondistinguishable for the two pore blockers (gentamicin and ruthenium red), although this profile is shared by other mechanosensitive channels. Thus, pharmacology cannot provide a unique signature for the hair cell transducer, but it does suggest that TRPA1 forms mechanosensitive channels (something that we presently cannot directly test for). Other channel properties, such as the conductance of $\sim 100 \mathrm{pS}$, are also similar, although the variable conductances of both TRPA1 and the hair cell transducer (determined on different species and types of hair cell, but also known to vary with the position of the hair cell) prevent a precise comparison. However, calcium has several characteristic and uncommon effects on the hair cell channel, and these effects are also observed in heterologously expressed TRPA1. First, calcium reduces the conductance to the same extent (54\%) on both channels. Second, calcium applied extracellularly causes an increase in activation speed (which we call potentiation) on both channels. To the extent that it is possible to compare these phenomena, detected with very different experimental preparations in each case (single-channel ensembles for mechanically activated hair cells and whole-cell records for AITC-activated, TRPA1-expressing HEK cells), the potential analogy is evident. Third, calcium entering the channel binds to a site within or very close to the channel and causes channel closure (referred to as fast adaptation for the hair cell transducer and as inactivation in our experimental setting). This calcium effect is voltage dependent in both cases. Fourth, sustained depolarization causes the reopening of the channels previously closed by calcium. These shared calcium-mediated phenomena suggest mechanistic similarities between the channels. However, large differences in timing of these events exist between the hair cell transducer (milliseconds) and TRPA1 (seconds). A probable scenario is that permeating calcium, once in the pore, either proceeds across the channel or binds to it to cause its effects. The higher the affinity for calcium of the binding site within the channel, the faster the kinetics. This affinity would depend on the microenvironment of the calciumbinding site on the channel, something which could easily vary between (1) a heterologously expressed TRPA1 homomultimeric channel with no accessory proteins and chemically activated with AITC, and (2) the endogenous hair cell transducer complex that is mechanically activated. The macromolecular differences between these two systems may also involve lipids, because the hair cell transducer is in a subcellular compartment rich in $\mathrm{PIP}_{2}$ (phosphatidylinositol 4,5-bisphosphate), and this polyphosphoinositide affects the speed of calcium-induced fast adaptation (Hirono et al., 2004). But despite the quantitative differences in timing, the mechanism of action of calcium appears qualitatively the same for both channels.

In conclusion, although some of the individual characteristics shared by the hair cell transducer and TRPA1 are also displayed by other channels, the combination of all common properties have not been reported for any other channel, either endogenous or heterologously expressed. Considering that TRPA1 shares a unique set of channel properties with the hair cell transducer, that its inhibition impairs hair cell transduction, and that it localizes to the site of transduction, we believe that TRPA1 is a poreforming component of the mechanosensory channel of hair cells.

In zebrafish, in addition to TRPA1, evidence also points to a similar TRP channel, NOMPC, as a component of the hair cell transducer (Sidi et al., 2003). NOMPC and TRPA1 distinguish themselves from other TRP channels by the large number of ankyrin repeats (29 and 17, respectively), a structural feature that could provide the attachment to the cytoskeleton and/or the gating spring that are believed to be inherent to the mechanosensory apparatus (Gillespie and Walker, 2001). It is likely that both NOMPC and TRPA1 contribute to hair cell transduction in fish. 
However, mammals do not have an NOMPC ortholog, so TRPA1 (alone or together with other channel proteins) may have fully replaced it in higher vertebrates as the transducer channel.

\section{TRPA1 as a nociceptor channel}

A role for TRPA1 as a painful cold receptor was initially proposed based on a reported expression in only $4 \%$ of the DRG neurons and activation by painful cold temperatures as well as by the cooling agent icilin (Story et al., 2003) (which also activates the cold-receptor channel TRPM8) (Peier et al., 2002). Later, it became apparent that a number of pain-producing chemicals could activate TRPAl and that it was expressed by a larger percentage of nociceptors (Jordt et al., 2004). Our thorough quantification of TRPA1 expression and localization reveals that it is present in most small-diameter neurons of all sensory ganglia that mediate nociception (dorsal root, trigeminal, and nodose). Furthermore, in our hands, cold temperatures cause no channel activation, although icilin does. We conclude that TRPA1 plays a role in nociceptors other than (or in addition to) cold sensation. Interestingly, icilin elicits both a cooling and a prickling sensation (Wei and Seid, 1983) (R. LaMotte, personal communication). Whereas the cooling effect can be explained by activation of TRPM8, the pricking could be attributable to activation of TRPA1.

It is formally possible that mouse TRPA1 is not a sensory receptor channel but that it instead plays a nonsensory role in nociceptor neurons. However, we do not favor this possibility for a number of reasons. First, mouse TRPA1 is almost exclusively expressed by nociceptors, with the exception being other sensory cells. A channel with a nonsensory role would be likely to be also used by other neurons. Second, in mouse nociceptors, TRPA1 is present at free nerve endings, where sensory transduction takes place. Third, TRPA1 is activated by numerous chemicals that produce sensations of pain when applied to nociceptor nerve endings. Fourth, in hair cells, TRPA1 is likely to be part of the transduction channel complex (Corey et al., 2004). By analogy, an equivalent role would be expected in nociceptors. Fifth, in nematodes, activation of TRPA1 elicits an avoidance response, the expected behavior when a nociceptor is stimulated (J. GarcíaAñoveros, unpublished results).

At least one of the channel properties that we describe for TRPA1, the hyperpolarization-dependent inactivation, is particularly well suited for the function of a pain receptor, because it can account for pain phenomena such as lack of desensitization, allodynia, and coincidence detection. Inactivation is uncharacteristic of some nociceptors, which stay active as long as the noxious stimulus lasts. By inactivating at hyperpolarized potentials $(-80 \mathrm{mV})$ but not at depolarized potentials $(-20 \mathrm{mV}$, which is normally reached during sustained stimulation of nociceptors), TRPA1 channels would not transmit subthreshold stimuli (which are to be ignored) even if these persist, and yet stay active in response to a sustained suprathreshold (i.e., noxious) stimulus.

But what form of nociception does TRPA1 mediate? Because icilin, isothiocyanates, and other chemical agonists of TRPA1 are not endogenous ligands, what endogenous stimuli (chemical, thermal, mechanical, a combination) activate TRPA1 in mammalian nociceptors? Although a definitive answer to this question will probably have to wait for the knock-out of this gene, our study leads to some suggestions.

The sensitivity of TRPA1 to so many chemicals is suggestive of a role in chemical nociception. However, the pharmacological profile of TRPA1 channels, which is common to mechanosensory channels, as well as the presence of TRPA1 in mechanosensory cells from nematodes (A. Duggan and J. García-Añoveros, unpublished observations) to mammals (hair cells), where it likely mediates mechanotransduction, suggests that TRPA1 could be a mechanonociceptor. These two functions are not mutually exclusive because, as is the case for other nociceptor channels, TRPA1 could be a polymodal receptor. In any case, the ample expression of TRPA 1 among nociceptor neurons suggests that it participates in a common form of pain, whereas its absence from major organs makes it an ideal target for drugs (analgesics or even antipruritics) with potentially no side effects (although targeting to the inner ear would have to be avoided).

\section{References}

Bandell M, Story GM, Hwang SW, Viswanath V, Eid SR, Petrus MJ, Earley TJ, Patapoutian A (2004) Noxious cold ion channel TRPA1 is activated by pungent compounds and bradykinin. Neuron 41:849-857.

Blair NT, Bean BP (2003) Role of tetrodotoxin-resistant $\mathrm{Na}^{+}$current slow inactivation in adaptation of action potential firing in small-diameter dorsal root ganglion neurons. J Neurosci 23:10338-10350.

Corey DP, García-Añoveros J, Holt JR, Kwan KY, Lin SY, Vollrath MA, Amalfitano A, Cheung EL, Derfler BH, Duggan A, Géléoc GS, Gray PA, Hoffman MP, Rehm HL, Tamasauskas D, Zhang DS (2004) TRPA1 is a candidate for the mechanosensitive transduction channel of vertebrate hair cells. Nature 432:723-730.

Crawford AC, Evans MG, Fettiplace R (1991) The actions of calcium on the mechano-electrical transducer current of turtle hair cells. J Physiol (Lond) 434:369-398.

Denk W, Holt JR, Shepherd GM, Corey DP (1995) Calcium imaging of single stereocilia in hair cells: localization of transduction channels at both ends of tip links. Neuron 15:1311-1321.

Duggan A, García-Añoveros J, Corey DP (2002) The PDZ domain protein PICK1 and the sodium channel $\mathrm{BNaCl}$ interact and localize at mechanosensory terminals of dorsal root ganglion neurons and dendrites of central neurons. J Biol Chem 277:5203-5208.

Farris HE, LeBlanc CL, Goswami J, Ricci AJ (2004) Probing the pore of the auditory hair cell mechanotransducer channel in turtle. J Physiol (Lond) 558 3:769-792.

García-Añoveros J, Samad TA, Zuvela-Jelaska L, Woolf CJ, Corey DP (2001) Transport and localization of the $\mathrm{DEG} / \mathrm{ENaC}$ ion channel $\mathrm{BNaC} 1 \alpha$ to peripheral mechanosensory terminals of dorsal root ganglia neurons. J Neurosci 21:2678-2686.

Géléoc GS, Lennan GW, Richardson GP, Kros CJ (1997) A quantitative comparison of mechanoelectrical transduction in vestibular and auditory hair cells of neonatal mice. Proc R Soc Lond B Biol Sci 264:611-621.

Gillespie PG, Walker RG (2001) Molecular basis of mechanosensory transduction. Nature 413:194-202.

Hamill OP, McBride Jr DW (1996) The pharmacology of mechanogated membrane ion channels. Pharmacol Rev 48:231-252.

Hasson T, Gillespie PG, Garcia JA, MacDonald RB, Zhao Y, Yee AG, Mooseker MS, Corey DP (1997) Unconventional myosins in inner-ear sensory epithelia. J Cell Biol 137:1287-1307.

Hirono M, Denis CS, Richardson GP, Gillespie PG (2004) Hair cells require phosphatidylinositol 4,5-bisphosphate for mechanical transduction and adaptation. Neuron 44:309-320.

Howard J, Hudspeth AJ (1988) Compliance of the hair bundle associated with gating of mechanoelectrical transduction channels in the bullfrog's saccular hair cell. Neuron 1:189-199.

Jaquemar D, Schenker T, Trueb B (1999) An ankyrin-like protein with transmembrane domains is specifically lost after oncogenic transformation of human fibroblasts. J Biol Chem 274:7325-7333.

Jordt SE, Bautista DM, Chuang HH, McKemy DD, Zygmunt PM, Hogestatt ED, Meng ID, Julius D (2004) Mustard oils and cannabinoids excite sensory nerve fibres through the TRP channel ANKTM1. Nature 427:260-265.

Jorgensen F, Ohmori H (1988) Amiloride blocks the mechano-electrical transduction channel of hair cells of the chick. J Physiol (Lond) 403:577-588

Kennedy HJ, Evans MG, Crawford AC, Fettiplace R (2003) Fast adaptation of mechanoelectrical transducer channels in mammalian cochlear hair cells. Nat Neurosci 6:832-836. 
Kimitsuki T, Nakagawa T, Hisashi K, Komune S, Komiyama S (1996) Gadolinium blocks mechano-electric transducer current in chick cochlear hair cells. Hear Res 101:75-80.

Kroese AB, Das A, Hudspeth AJ (1989) Blockage of the transduction channels of hair cells in the bullfrog's sacculus by aminoglycoside antibiotics. Hear Res 37:203-217.

Peier AM, Moqrich A, Hergarden AC, Reeve AJ, Andersson DA, Story GM, Earley TJ, Dragoni I, McIntyre P, Bevan S, Patapoutian A (2002) A TRP channel that senses cold stimuli and menthol. Cell 108:705-715.

Pickles JO, Corey DP (1992) Mechanoelectrical transduction by hair cells. Trends Neurosci 15:254-259.

Ricci A (2002) Differences in mechano-transducer channel kinetics underlie tonotopic distribution of fast adaptation in auditory hair cells. J Neurophysiol 87:1738-1748.

Ricci AJ, Wu YC, Fettiplace R (1998) The endogenous calcium buffer and the time course of transducer adaptation in auditory hair cells. J Neurosci 18:8261-8277.

Ricci AJ, Crawford AC, Fettiplace R (2000) Active hair bundle motion linked to fast transducer adaptation in auditory hair cells. J Neurosci 20:7131-7142.

Ricci AJ, Crawford AC, Fettiplace R (2003) Tonotopic variation in the conductance of the hair cell mechanotransducer channel. Neuron 40:983-990.
Rüsch A, Kros CJ, Richardson GP (1994) Block by amiloride and its derivatives of mechano-electrical transduction in outer hair cells of mouse cochlear cultures. J Physiol (Lond) 474:75-86.

Schaeren-Wiemers N, Gerfin-Moser A (1993) A single protocol to detect transcripts of various types and expression levels in neural tissue and cultured cells: in situ hybridization using digoxigenin-labelled cRNA probes. Histochemistry 100:431-440.

Sidi S, Friedrich RW, Nicolson T (2003) NompC TRP channel required for vertebrate sensory hair cell mechanotransduction. Science 301:96-99.

Siemens J, Lillo C, Dumont RA, Reynolds A, Williams DS, Gillespie PG, Muller U (2004) Cadherin 23 is a component of the tip link in hair-cell stereocilia. Nature 428:950-955.

Story GM, Peier AM, Reeve AJ, Eid SR, Mosbacher J, Hricik TR, Earley TJ, Hergarden AC, Andersson DA, Hwang SW, McIntyre P, Jegla T, Bevan S, Patapoutian A (2003) ANKTM1, a TRP-like channel expressed in nociceptive neurons, is activated by cold temperatures. Cell 112:819-829.

Walker RG, Willingham AT, Zuker CS (2000) A Drosophila mechanosensory transduction channel. Science 287:2229-2234.

Wei ET, Seid DA (1983) AG-3-5: a chemical producing sensations of cold. J Pharm Pharmacol 35:110-112.

Yang XC, Sachs F (1989) Block of stretch-activated ion channels in Xenopus oocytes by gadolinium and calcium ions. Science 243:1068-1071. 